\title{
Increased Plasma Level of IGFBP4 in Obstructive Sleep Apnea Patients and the Restoration of its level Through Multilevel Sleep Surgery
}

Abdulmohsen Alterki

Dasman Diabetes Institute

Eman Al Shawaf

Dasman Diabetes Institute

Irina Al-Khairi

Dasman Diabetes Institute

Preethi Cherian Preethi Cherian

Dasman Diabetes Institute

Devarajan Sriraman

Dasman Diabetes Institute

Maha Hammad

Dasman diabetes institute

Alphonse T. Thangavel

Dasman Diabetes Institute

Mahmoud A Ebrahim

Zain hospital

Fahd Al-Mulla

Dasman Diabetes Institute

Mohamed Abu-Farha

Dasman Diabetes Institute

Jehad Abubaker ( $\sim$ jehad.abubakr@dasmaninstitute.org )

Dasman Diabetes Institute

Original investigation

Keywords: IGFBP4, IGFBP7, Hypoxia, AHI, OSA

Posted Date: December 30th, 2020

DOl: https://doi.org/10.21203/rs.3.rs-137387/v1 
License: (c) (i) This work is licensed under a Creative Commons Attribution 4.0 International License. Read Full License 


\section{Abstract}

Background: IGFBP4 is the smallest member of the insulin-like growth factor binding protein family (IGFBP). It's a hepatic protein that plays a role in modulating the activity and bioavailability of IGF-I. The expression of IGFBP4 was found to increase under conditions of hypoxia. Obstructive Sleep Apnea (OSA) is a common disorder, characterized by cyclic episodes of intermittent hypoxia and fragmented sleep.

Methods: We quantified levels of circulating IGFBP1, IGFBP2, IGFBP3, IGFBP4 and IGFBP7 in fasting plasma samples of 67 Kuwaiti participant using Multiplexing assay. The study involved 28 controls, and 39 patients with OSA.

Results: Levels of circulating IGFBP4 were significantly higher in people with OSA $(253.65 \pm 20.46 \mathrm{ng} / \mathrm{ml})$ compared to the control group ( $173.35 \pm 20.86 \mathrm{ng} / \mathrm{ml}, p=0.008)$. There was an increase in levels of IGFBP3 and IGFBP7, however it was not significant. People with OSA had a significantly high AHI score $(22.99 \pm 3.39$ events/h) in comparison to the control $(2.12 \pm 0.2$ events/h). The increase in IGFBP4 correlated positively to IGFBP7 $(r=0.422, P=0.01)$. There was a significant decline in circulating IGFBP4 after 3-months of surgery $(225.89 \pm 18.16 \mathrm{ng} / \mathrm{ml}, p=0.012)$. This was accompanied by a prominent improvement in OSA (AHI $8.97 \pm 2.37$ events $/ \mathrm{h}, p=0.001)$.

Conclusion: In this study our data showed a significant increase in circulating IGFBP4 in people with OSA. we also report a significant positive correlation between IGFBP4 and IGFBP7 at baseline, which suggests a potential synergy in the actions of IGFBP4 and IGFBP7 at conditions of OSA-induced hypoxia. OSA significantly improved after 3-month of surgical intervention, which concurred with a significant decline in IGFBP4 levels. Altogether, this suggests a potential role for IGFBP4 in OSA-induced hypoxia.

\section{Introduction}

Obstructive sleep Apnea (OSA) is a chronic sleep disorder that features fragmented sleep. It is characterized by having repeated episodes of airflow cessation (apnea), or airflow reduction (hypopnea), which leads to intermittent hypoxia (i.e. a decline in oxyhemoglobin saturation), interrupted sleep, and augmented heart rate oscillations, intrathoracic pressure, and hypertension $(1,2)$. The chronic presence of these disruptions activates various pathological mechanisms that would elicit vascular damage and might play a role in the development of cardiovascular morbidities $(1,3)$. OSA is a common disorder that is mostly prevalent among people with obesity (1), and has been associated with diabetes and cardiovascular disease (CVD) (4).

OSA treatment options involve lifestyle modifications, weight reduction, and the use of surgical procedures or external therapies that help keeping an open airway during sleep. Continuous positive airway pressure (CPAP) is the primary treatment as it was one of the first discovered and yielded the fastest recovery rates, but adherence rates are low, especially for those with minimal symptoms. Studies found weight loss to concur with a reduced apnea-hypopnea index $(\mathrm{AHI})$ that indicates an abated severity, and improved apnea symptoms in people with obesity and OSA $(5,6)$. Weight-loss surgeries proved to be 
a better option for a rapid and efficient weight reduction. Therefore, the clinical guidelines for bariatric surgery strongly recommends considering a surgical weight-loss procedure to treat people with obesity and OSA (7). Although the loss of excess weight per se is an important factor to relieve symptoms of OSA, ENT surgical interventions are the most effective methods for OSA management at the present time. These surgeries mitigate symptoms of OSA by improving the strength of the upper airway to reduce upper airway obstruction. ENT procedures involve nasal, palate, tongue and maxilla-madibular surgeries (8). Adenotonsillectomy and tonsillectomy, are the most common procedures performed as an initial therapy. Nonetheless, OSA involves one or more upper airway levels. Thus, a multilevel sleep surgery (MLS) in a single-stage procedure has been developed as a surgical treatment method for OSA patients that require surgery, with a success rate reaching $60 \%(9,10)$. Whilst post-surgery improvement is evident, the mechanisms/biochemical factors that are related to OSA and involved in the post-surgery improvement are yet to be identified.

The family of Insulin-like growth factor binding proteins (IGFBPs) comprises a group of high-affinity binding proteins (IGFBP1 - IGFBP6) (11). An additional member is IGFBP related protein-1 (IGFBP-rp1), which possess up to $45 \%$ similarity to other IGFBPs and is better known as IGFBP7 (12). Although highly similar, IGFBP7 differs in lacking the conserved c-terminus cysteines and having a reduced affinity for IGF-I but a strong affinity to insulin (13). These proteins play a critical role in the GH/IGF system, by regulating the bioavailability and modulating the signaling of Insulin-like growth factor (IGF) ligands (11). The GH/IGF system and IGFBPs are influenced by sleep and sleep disordered breathing $(14,15)$. This suggests a potential involvement of IGFBPs in OSA or its related mechanisms. Members of the IGFBP family are involved in various cellular processes such as, cell proliferation, differentiation, migration and apoptosis, which explains their contribution to various physiological and pathological processes $(11,16)$.

The hepatic IGFBP1 is involved in various processes like, insulin sensitivity (17), glucose regulation (17), and cardiovascular pathophysiology $(17,18)$. The expression of IGFBP1 is raised at stressful conditions such as hypoxia and starvation to limit the activity of IGFs, and consequently reduce the rate of growth and development (16). Regulating cell growth and apoptosis was also reported with IGFBP3, which is the most abundant protein of the IGFBP family (19). Low levels of circulating IGFBP3 has been associated with an increased CVD risk and higher mortality $(20,21)$. In relation to OSA, the severity of sleep apnea (indicated by AHI score) correlated negatively with IGF-I levels, which was independent of BMI and age $(14,15)$. The importance of IGFBP3 was emphasized by showing a link between decreased levels of circulating IGFBP3 and growth retardation in children with OSA (22). IGFBP4, the smallest member of the IGFBPs is thought to have a complex activity that is cell type and tissue-specific (23). Studies have reported a critical role for IGFBP4 in vascular tissue physiology and pathophysiology, where it functioned as a regulator of smooth muscle cell proliferation $(11,23,24)$. This implicated a potential involvement of IGFBP4 in an OSA-induced effect.

The aim of this study was to measure circulating levels of IGFBPs in adult OSA patients and compare them to control participants. We also investigated the association between IGFBPs and OSA indicators in 
adults to identify novel biomarkers. Additionally, we explore the use of surgical interventions as a treatment option and its effect on OSA and IGFBPs levels.

\section{Materials \& Methods}

\section{Study population \& design}

The study involved a total of 67 participant; of these 39 with OSA indicated by AHI $>5$ events $/ \mathrm{h}$, and 28 were control defined by AHI $<5$ events/h. Type I polysomnography (PSG) test was performed in level 1 sleep laboratory to determine the presence of sleep apnea. Participants were matched for age- and body mass index (BMI). Inclusion criteria was those who underwent MLS and completed a pre-operative and post-operative level 1 polysomnography (PSG), pre-operative and post-operative Epworth Sleepiness Scale (ESS), Pre-operative and post-operative blood metabolites, and we recorded their medical history, and patient's data, such as BMI. The study excluded people with CVDs, diabetes and a history of any major illness. Study approval was obtained by the Ethical Review Board of Dasman Diabetes Institute (DDI), and it was conducted in accordance with the ethical guideline outlined in the Declaration of Helsinki. Written consents were obtained from all participants prior to their enrollment in the study.

\section{Biochemical and anthropometric measurements}

Fasting blood samples were obtained from all participants. Plasma was extracted from blood samples collected in vacutainer (EDTA tubes), after $400 \mathrm{Xg}$ centrifugation for $10 \mathrm{~min}$. Collected plasma samples were aliquoted and stored at $-80^{\circ} \mathrm{C}$ until assayed. Blood pressure was measured by the Omron HEM907XL digital sphygmomanometer. The final reading represented the average of three consecutive readings. Fasting blood glucose (FBG), serum total cholesterol (TC), low-density lipoprotein (LDL-C), highdensity lipoprotein (HDL-C) and triglycerides (TG) were measured by Siemens Dimension RXL chemical analyzer (Diamond Diagnostics, Holliston, MA, USA). Hemoglobin A1c was quantified by the Variant ${ }^{\text {TM }}$ device (Bio-Rad, Hercules, CA).

\section{OSA assessment and surgery}

The study population was diagnosed using Type I PSG test as detailed (25). This test involves an overnight sleep in a sleep lab, during which biophysiological data was captured to formulate a comprehensive picture of participants' sleep architecture. Type I PSG includes monitoring blood oxygen levels, breathing patterns, brain activity (EEG), eye movement (EOG), heart rhythm (ECG) and skeletal muscle activity (EMG) during sleep. Data reflecting airflow and respiratory effort is used to calculate the Apnea-Hypopnea Index (AHI). The apnea Index (Al) indicated the number of events at which respiration is completely ceased for $>10 \mathrm{sec} / \mathrm{hr}$, while hypopnea index $(\mathrm{HI})$ reflected the number of partial airway obstruction events per hour. Diagnosis of OSA is based on participant's AHI score, where a score of $>5$ events/h of sleep is defined as an abnormal sleep. The presence of a high AHI score, and its occurrence with enormous daytime sleepiness indicated a positive case of OSA. AHI score is used to evaluate the severity of OSA, with AHI score of 5 to 15 events/h reflected mild OSA, AHI of 15-30 events/h indicated a 
moderate level, and AHI score $>30$ events/h defined a condition of sever OSA (26). All participants that underwent surgeries were carefully selected and an individualized procedure was performed for each participant. All surgeries involved tonsillectomy in addition to other corrections such as the nasal cavity, nasopharynx, and/or hypopharynx depending on the cause of upper-airway collapse.

\section{IGFBPs quantitative assays}

levels of IGFBP1, $-2,-3,-4$ and -7 were determined by the Magnetic Luminex Assay kit (R\&D Systems Europe, Ltd, Abingdon, UK) following manufacturer's protocol.

\section{Statistical analysis}

Student's t-test was employed to study the difference between people with and without OSA. One-way Analysis of variance (ANOVA) was performed to compare data of the control and OSA subgroups, i.e. mild, moderate and severe OSA. The correlation between IGFBP4 and OSA was estimated by Spearman's correlation coefficient. All data were presented as mean \pm SEM, with a $P$-value $<0.05$ indicating significance. Received operating curve (ROC) analysis was performed to study the utility of IGFBP4 as a marker identifying people with OSA. All statistical analysis was performed using SAS (version 9r; SAS Institute) and SPSS for windows version 25.0 (IBM SPSS Inc., USA).

\section{Results}

\section{Study population characteristics}

Table 1 summarizes the general characteristics of our study population. The study groups were classified into control and OSA groups that were age and BMI matched. Control participants had a mean age of 40 \pm 1 years, while participants with OSA had a mean age of $43 \pm 2$ years $(p=0.246)$. The mean BMI in the control group was $28.59 \pm 0.99 \mathrm{~kg} / \mathrm{m}^{2}$, while OSA participants had a BMI of $30.2 \pm 0.63 \mathrm{~kg} / \mathrm{m}^{2}(p=$ 0.181). There was no significant difference in parameters of the lipid profile comparing control group with the OSA group, and this included levels of total Chol, TG and LDL with the exception of HDL where people with OSA showed a significantly reduced HDL levels $1.08 \pm 0.04 \mathrm{mmol} / \mathrm{L}(p=0.037)$ compared to the control group $1.25 \pm 0.07 \mathrm{mmol} / \mathrm{L}$ (Table 1).

\section{Polysomnography for OSA diagnosis:}

The AHI score was used to diagnose people with OSA and classify patients into three subgroups according to OSA severity, i.e. mild, moderate and severe. As presented in (Fig. 1), people with OSA had significantly higher OSA indices score compared to the control participants. People with OSA had higher number of apnea events, $\mathrm{Al}=3.01 \pm 0.92$ events $/ \mathrm{h}(p<0.05)$ and hypopnea events, $\mathrm{HI}=17.53 \pm 2.74$ events $/ \mathrm{h}(p<0.001)$, compared to the control group $\mathrm{Al}=1.18 \pm 0.21$ events $/ \mathrm{h}$ and $\mathrm{HI}=1.54 \pm 0.28$ events/h. Collectively this was reflected by the AHI score, which was significantly higher in people with OSA, $22.99 \pm 3.39$ events/h, compared to the control group $\mathrm{AHI}=2.12 \pm 0.26$ events $/ \mathrm{h}, p<0.001$. The subclassification was used to study changes in levels of circulating IGFBPs at various OSA levels. 


\section{Baseline levels of plasma IGFBPs:}

Levels of plasma IGFBPs were different between people with OSA and control participants (Fig. 2). Although not significant, people with OSA showed lower level of IGFBP1 and IGFBP2. People with OSA had lower levels of IGFBP1 $(10695.42 \pm 1510.3 \mathrm{ng} / \mathrm{ml})$ compared to the control group $(14687.01 \pm$ $2692.49 \mathrm{ng} / \mathrm{ml}, p=0.203)$, and levels of IGFBP2 in people with OSA $(213922.55 \pm 12632.2 \mathrm{ng} / \mathrm{ml})$ were lower than the control $(269837.02 \pm 31643.27 \mathrm{ng} / \mathrm{ml}, p=0.139)$. On the other hand, levels of IGFBP3 $(756438.94 \pm 30196.72 \mathrm{ng} / \mathrm{ml})$ in people with OSA were higher than the control group $(721032.69 \pm$ $40291.55 \mathrm{ng} / \mathrm{ml}, p=0.485)$, and levels of IGFBP7 (18822.84 $\pm 1201.21 \mathrm{ng} / \mathrm{ml})$ were higher in people with OSA compared to the control group $(17622.79 \pm 1810.54 \mathrm{ng} / \mathrm{ml}, p=0.234)$. Levels of IGFBP4 were significantly higher in people with OSA $(253.65 \pm 20.46 \mathrm{ng} / \mathrm{ml}, p=0.008)$, compared to the control group $(173.35 \pm 20.86 \mathrm{ng} / \mathrm{ml})$. In the OSA subgroups (Fig. 3.A) IGFBP4 was highest in people with mild OSA $(276.93 \pm 36.02 \mathrm{ng} / \mathrm{ml})$, followed by people with moderate OSA $(254.74 \pm 28.68 \mathrm{ng} / \mathrm{ml})$ and it was lowest in people with severe OSA $(221.51 \pm 44.7 \mathrm{ng} / \mathrm{ml})$.

\section{IGFBP4 has a moderate predictive sensitivity for people with OSA}

Spearman's correlation analysis was conducted to investigate a potential correlation between IGFBPS, and biomarkers related to OSA. According to our results, the significant increase in IGFBP4 at baseline was not correlated to any OSA - related parameter. However, IGFBP4 was significantly correlated with IGFBP7 $(r=.422, p=.011)$. To further examine the significance of IGFBP4 in OSA, we performed receiver operating characteristic (ROC) curve analysis (27). ROC was used to assess IGFBP4 as a marker differentiating people with OSA from those without OSA (Fig. 3.B). Our analysis showed that IGFBP4 at a threshold of $0.127 \mu \mathrm{g} / \mathrm{ml}$, IGFBP4 presented a moderate sensitivity (81\%) and specificity (64\%). Additionally, IGFBP4 showed a positive predictive value of $61.3 \%$ and a negative predictive value of $58.4 \%$. ROC curve identified subjects with OSA significantly for IGFBP4, with an area under the curve (AUC) for IGFBP4 $=0.66$ and $p=0.025$.

\section{A surgical intervention induced improvement in AHI score and IGFBP4 levels}

To evaluate the effect of surgical intervention on OSA, we studied changes after 3 months of surgery. Our post-surgery data showed a significant improvement in AHI score $(8.97 \pm 2.3$ events/h, $p<0.001)$ after 3 months (Fig. 4). There was a decline in HI score after 3-months of surgery (6.63 \pm 1.99 events/h) but the change was not significant compared to baseline score. In our study population, IGFBP4 was the only protein that was significantly reduced $(225.89 \pm 18.16 \mathrm{ng} / \mathrm{ml}, p=0.012)$ after 3-months of surgery (Fig. 4). The change in other IGFBPs after surgery was not statistically significant (Table 2).

\section{Discussion}


OSA is increasingly becoming a major health problem that is aggravated with the global increase in incidence of obesity, diabetes, and CVD. In this study we report for the first time the increased levels of circulating IGFBP4 in people with OSA compared to people without OSA. This increase was more prominent with reduced OSA severity, where patients with mild and moderate OSA presented higher levels of IGFBP4. Furthermore, we identified IGFBP4 as a marker for people with OSA through ROC analysis. Additionally, we found higher levels of IGFBP3 and IGFBP7 in people with OSA, however in comparison to the control the increase was not significant. Using Spearman's correlation, we found that IGFBP4 and IGFBP7 correlated positively in people with OSA. This implicated a potential link between OSA-related factor(s) and the rise in IGFBPs specifically IGFBP4 in the current study. We also demonstrated the positive impact of MLS on IGFBP4 and the treatment of OSA, where IGFBP4 and AHI values were significantly reduced after the surgery.

Obstructive sleep apnea is the most prevalent form of sleep-disordered breathing conditions affecting people with obesity. People with OSA experience intermittent hypoxia that is induced by repeated episodes of hypopnea and apnea. Intermittent hypoxia has been found to promote oxidative stress, systemic and vascular inflammation and endothelial dysfunction (28). It was also reported to cause gradual progression of daytime hypertension and the consequent long-term cardiovascular comorbidities. One of the systems affected by OSA is the GH/IGF axis. Due to its circadian rhythm, the activity of GH/IGF-I is influenced by disturbed sleep patterns (29). Previous studies showed that people with obesity and OSA had an impaired GH/IGF-I axis function (29), however the effect of OSA on this axis was lost with increased age (22). In a study by Ursavas et. al, the presence of OSA per se was shown as a risk factor to having low IGF-I levels (15). In a similar manner to the GH/IGF-I axis, IGFBPs are also governed by circadian regulatory mechanisms (30) and they contribute substantially to regulating the activity and bioavailability of IGF-I.

OSA is characterized by cyclic episodes of complete or partial occlusion of the upper airway, leading to fragmented sleep, hypoxemia and hypercapnia. The repeated events of arousal and de-saturation during sleep causes an Intermittent hypoxia/re-oxygenation damage (IHR). Chronic hypoxia is a key feature of OSA and it can lead to pathophysiological complications such as; arterial hypertension (31), coronary artery disease (32), myocardial infarction (33) or other cardiovascular complications as atherosclerosis (34). This is in addition to various metabolic and cognitive consequences and risk of cancer (33). Previous studies reported increased expression of IGFBP1, IGFBP3 (35) and IGFBP4 (36) in response to hypoxia. However, the link between IGFBPs and OSA is not clear (22). In our study, we found an increase in baseline IGFBP3, IGFBP4 and IGFBP7 in people with OSA compared to the control group. This elevation was significant with IGFBP4, but not IGFBP3 or IGFBP7 (Fig. 2). Hypoxia is known to upregulate the expression of IGFBP4 (36) and other IGFBPs (35), which can be the reason for its increased level in OSA. Accordingly, performing corrective upper airway surgeries would relieve the obstructed airflow, resulting in improved hypoxic conditions that consequently reduces IGFBP4 level (Fig. 4).

The detected rise in IGFBP4 in people with OSA correlated positively and significantly with IGFBP7. However, the increase in circulating IGFBP7 at baseline was not significant in comparison to control 
participants. Previous studies showed a positive correlation between IGFBP4 and age (24). However, in our study the increase in IGFBP4 appeared to occur independent of age, since it was limited to people with OSA. Although the rise in IGFBP4 did not show a significant correlation with OSA indices, we found that it can be utilized as a marker differentiating between people with OSA and those without OSA (Fig. 3.B). This was emphasized by ROC analysis, which presented IGFBP4 as a marker with moderate sensitivity (81\%) and specificity (64\%) for people with OSA. Furthermore, we found that mild OSA concurred with an increase in circulating IGFBP4. The elevation in IGFBP4 levels tuned down with increased OSA severity so that IGFBP4 was lowest in patients with severe OSA. Although our data highlights a link between OSA and elevated levels of IGFBP4, this finding contradicts the upregulation of IGFBP4 expression in response to hypoxia (36). According to the finding of Minchenko et. al, we would speculate a concomitant rise in IGFBP4 and OSA severity due to increased hypoxia, which is not reflected by our results. Nonetheless, the increase in IGFBP4 levels with mild OSA might be suggestive of an early role for this protein, whereby IGFBP4 may act as an early stage marker for OSA. A similar observation was reported with leptin, where people with sever OSA presented lower levels of circulating leptin (37).

Our data also showed an increase in circulating IGFBP3 in people with OSA, which was not significant (Table 1). Additionally, we found no association between IGFBP3 and OSA indices. This comes in agreement with a previous report, which did not find a significant association between IGFBP1, IGFBP3 and measures of OSA (22). Interestingly, post-surgery measurements showed a significant improvement in OSA status after 3-months of surgery, reflected by AHI score (Fig. 4.A). The improvement in AHI score was concomitant with a significant decline in circulating IGFBP4 (Fig. 4.B). This emphasized a link between IGFBP4 and OSA-induced hypoxia as well as the role that IGFBP4 can play in the diagnosis and prognosis of OSA.

In this study, our data accentuated a potential role for IGFBP4 in OSA-induced hypoxia. Nonetheless, the functional significance of this association is not clear yet. IGFBP4 is the smallest member of the IGFBPs family and it is mainly produced by the liver (38). It is also the main IGFBP produced by aortic vascular smooth muscle cells (39). IGFBP4 plays a critical role in the vascular tissue in normal and pathological settings. This was shown through its effect on thrombin-induced DNA synthesis (24), and its role in inhibiting atherosclerotic lesion formation (16). Circulating IGFBP4 is found at low levels, and its role involves modulating the bioavailability of IGF-I (38). However, at conditions of overexpression it acted as an antagonist of IGF-I actions on smooth muscle cells (24). A rise in IGFBP4 levels had an inhibitory effect on cell proliferation, and stimulated apoptosis (40). The fact that increased levels of IGFBP4 eliminates the bioavailability of IGF-I, explains its antiproliferative actions.

The rise in IGFBP4 concurred with an increase in IGFBP7, which implicated a potential link between their actions. IGFBP7 is acknowledged as a marker of acute kidney injury (41). Increased levels of IGFBP7 were detected with conditions of hypoxia, and atherosclerotic renal artery stenosis due to decreased renal blood flow (42). Interestingly, the rise in IGFBP7 was reported with pathological conditions, however the protein was suggested to play a protective role by reducing acute tissue changes caused by hypoxia (42). The role of IGFBP7 was proposed to resemble ischemic preconditioning, which is a protective 
mechanism. Although higher IGFBP7 is an acknowledged predictive biomarker of acute kidney injury, others interpreted its role as being protective (43). The protective actions of IGFBP7 were attributed by its possible role in potentiating a natural defense mechanism such as temporary cell cycle arrest $(42,44)$. Currently, our understanding of the significance and the physiological importance of the increase in IGFBP4 and IGFBP7 is limited. Further studies are required to elucidate the functional importance of IGFBP4 and IGFBP7 in OSA. The main limitation of this study is the limited number of participants dictated by the nature of our study with surgery intervention.

\section{Conclusions}

In conclusion, we report a significant increase in circulating IGFBP4 in a group of adults with OSA, and we present IGFBP4 as an OSA marker with moderate sensitivity and specificity. IGFBP4 correlated with IGFBP7 at baseline, which propounds a potential link/synergy in the actions of IGFBP4 and IGFBP7 at conditions of OSA-induced hypoxia. Three months following a surgical intervention there was a significant improvement in OSA, which concurred with a significant decline in circulating IGFBP4. Although the functional significance of this finding is obscure, it suggests IGFBP4 as a biomarker for OSA-induced hypoxia. The repeated episodes of hypoxia/re-oxygenation would induce a chronic injury pathway, which might be counteracted by increased expression of IGFBP7 and IGFBP4.

\section{Abbreviations}

Obstructive sleep apnea (OSA), Apnea-Hypopnea Index (AHI), Apnea Index (AI), Hypopnea Index (HI), polysomnography (PSG), Growth hormone (GH), insulin-like growth factor binding proteins (IGFBPs), insulin-like growth factor (IGF), Body mass index (BMI), Systolic and diastolic blood pressure (SBP, DBP), High density lipoprotein (HDL), Low density lipoprotein (LDL), Total cholesterol (TC), Triglycerides (TG), High sensitivity c-reactive protein (hsCRP), Fasting blood glucose (FBG), Hemoglobin A1c (HbA1c), Brain activity (EEG), Eye activity (EOG), Hearth rhythm (ECG), Skeletal muscle activity (EMG).

\section{Declarations}

\section{Ethics approval and consent to participate}

This study was approved by the Ethical Review Board of Dasman Diabetes Institute (DDI), Kuwait, and it was conducted in accordance with the ethical guideline outlined in the Declaration of Helsinki. Written consents were obtained from all participants prior to their enrollment in the study.

\section{Consent of publication}

Not applicable

\section{Availability of data and materials}


The datasets included in this study are not available for sharing from the corresponding author(s) due to unpublished data and ethical restrictions by the institute.

\section{Competing interests}

The authors declare that they have no competing interests.

\section{Funding}

This work was supported by the Kuwait Foundation for the Advancement of Sciences (KFAS) under project number (RA-2015-043).

\section{Authors' contribution}

Abdulmohsen Al-Terki: study design, sole surgeon and sleep study data interpretation; Eman AlShawaf: data analysis and wrote the manuscript; Mohamed Abu-Farha: study design and directed laboratory investigation and critically revising the manuscript; Irina Al-Khairi and Preethi Cherian: performing ELISA assay and critical revision of manuscript; Devarajan Sriraman: analyzing and managing data; Mahmoud A K Ebrahim: collecting the data from the patients; Fahd Al-Mulla: interpreting data and critical revision of the manuscript; Jehad Abubaker: designing the study, interpreting data and critically revising the manuscript.

\section{Acknowledgments}

The authors of this study acknowledge the support and contribution of the Clinical Laboratory and the Tissue Bank Core Facility at DDI. We are grateful for the financial and logistic support provided by KFAS and DDI to facilitate this research.

\section{References}

1. Peppard PE, Young T, Barnet JH, Palta M, Hagen EW, Hla KM. Increased prevalence of sleepdisordered breathing in adults. Am J Epidemiol. 2013;177(9):1006-14.

2. Somers VK, White DP, Amin R, Abraham WT, Costa F, Culebras A, et al. Sleep apnea and cardiovascular disease: an American Heart Association/American College of Cardiology Foundation Scientific Statement from the American Heart Association Council for High Blood Pressure Research Professional Education Committee, Council on Clinical Cardiology, Stroke Council, and Council on Cardiovascular Nursing. J Am Coll Cardiol. 2008;52(8):686-717.

3. Shamsuzzaman AS, Gersh BJ, Somers VK. Obstructive sleep apnea: implications for cardiac and vascular disease. Jama. 2003;290(14):1906-14.

4. Shah NA, Yaggi HK, Concato J, Mohsenin V. Obstructive sleep apnea as a risk factor for coronary events or cardiovascular death. Sleep Breath. 2010;14(2):131-6. 
5. Lettieri CJ, Eliasson AH, Greenburg DL. Persistence of obstructive sleep apnea after surgical weight loss. J Clin Sleep Med. 2008;4(4):333-8.

6. Shechter A, St-Onge M-P, Kuna ST, Zammit G, RoyChoudhury A, Newman AB, et al. Sleep Architecture Following a Weight Loss Intervention in Overweight and Obese Patients with Obstructive Sleep Apnea and Type 2 Diabetes: Relationship to Apnea-Hypopnea Index. J Clin Sleep Med. 2014;10(11):1205-11.

7. Dong Z, Hong BY, Yu AM, Cathey J, Shariful Islam SM, Wang C. Weight loss surgery for obstructive sleep apnoea with obesity in adults: a systematic review and meta-analysis protocol. BMJ Open. 2018;8(8):e020876.

8. Sarkissian L, Kitipornchai L, Cistulli P, Mackay G. S. Current management of adult OSA. Australian Journal for General Practitioners. 2019;48:182-6.

9. Kotecha BT, Hall AC. Role of surgery in adult obstructive sleep apnoea. Sleep medicine reviews. 2014;18(5):405-13.

10. Verse T. [Update on surgery for obstructive sleep apnea syndrome]. Hno. 2008;56(11):1098-104.

11. Clemmons DR. Role of IGF-binding proteins in regulating IGF responses to changes in metabolism. J Mol Endocrinol. 2018;61(1):T139-T69.

12. Oh Y, Nagalla SR, Yamanaka Y, Kim HS, Wilson E, Rosenfeld RG. Synthesis and characterization of insulin-like growth factor-binding protein (IGFBP)-7. Recombinant human mac25 protein specifically binds IGF-I and -II. J Biol Chem. 1996;271(48):30322-5.

13. Akiel M, Rajasekaran D, Gredler R, Siddiq A, Srivastava J, Robertson C, et al. Emerging role of insulinlike growth factor-binding protein 7 in hepatocellular carcinoma. J Hepatocell Carcinoma [Internet]. 2014 2014; 1:[9-19 pp.]. Available from: http://europepmc.org/abstract/MED/27508172.

14. https://doi.org/10.2147/JHC.S44460.

15. Johnsen SP, Hundborg HH, Sorensen HT, Orskov H, Tjonneland A, Overvad K, et al. Insulin-like growth factor (IGF) I, -II, and IGF binding protein-3 and risk of ischemic stroke. J Clin Endocrinol Metab. 2005;90(11):5937-41.

16. Ursavas A, Karadag M, Ilcol YO, Ercan I, Burgazlioglu B, Coskun F, et al. Low level of IGF-1 in obesity may be related to obstructive sleep apnea syndrome. Lung. 2007;185(5):309-14.

17. Allard JB, Duan C. IGF-Binding Proteins: Why Do They Exist and Why Are There So Many? Front Endocrinol (Lausanne). 2018;9:117-.

18. Heald AH, Cruickshank JK, Riste LK, Cade JE, Anderson S, Greenhalgh A, et al. Close relation of fasting insulin-like growth factor binding protein-1 (IGFBP-1) with glucose tolerance and cardiovascular risk in two populations. Diabetologia. 2001;44(3):333-9.

19. Rajwani A, Ezzat V, Smith J, Yuldasheva NY, Duncan ER, Gage M, et al. Increasing Circulating IGFBP1 Levels Improves Insulin Sensitivity, Promotes Nitric Oxide Production, Lowers Blood Pressure, and Protects Against Atherosclerosis. Diabetes. 2012;61(4):915-24. 
20. Jogie-Brahim S, Feldman D, Oh Y. Unraveling Insulin-Like Growth Factor Binding Protein-3 Actions in Human Disease. Endocr Rev. 2009;30(5):417-37.

21. Juul A, Scheike T, Davidsen M, Gyllenborg J, Jørgensen T. Low serum insulin-like growth factor I is associated with increased risk of ischemic heart disease: a population-based case-control study. Circulation. 2002;106(8):939-44.

22. Friedrich N, Haring R, Nauck M, Lüdemann J, Rosskopf D, Spilcke-Liss E, et al. Mortality and serum insulin-like growth factor (IGF)-I and IGF binding protein 3 concentrations. J Clin Endocrinol Metab. 2009;94(5):1732-9.

23. Shah N, Rice T, Tracy D, Rohan T, Buzkova P, Newman A, et al. Sleep and insulin-like growth factors in the Cardiovascular Health Study. J Clin Sleep Med. 2013;9(12):1245-51.

24. Contois LW, Nugent DP, Caron JM, Cretu A, Tweedie E, Akalu A, et al. Insulin-like growth factor binding protein-4 differentially inhibits growth factor-induced angiogenesis. J Biol Chem. 2012;287(3):177989.

25. Durai R, Davies M, Yang W, Yang SY, Seifalian A, Goldspink G, et al. Biology of insulin-like growth factor binding protein-4 and its role in cancer (review). Int J Oncol. 2006;28(6):1317-25.

26. Alterki A, Joseph S, Thanaraj TA, Al-Khairi I, Cherian P, Channanath A, et al. Targeted Metabolomics Analysis on Obstructive Sleep Apnea Patients after Multilevel Sleep Surgery. Metabolites. 2020;10(9):358.

27. Al Lawati NM, Patel SR, Ayas NT. Epidemiology. Risk Factors, and Consequences of Obstructive Sleep Apnea and Short Sleep Duration. Prog Cardiovasc Dis. 2009;51(4):285-93.

28. Shi YK, Chen JX, Huang Y, Li AY. Serum. S100A12 levels are associated with the presence and severity of obstructive sleep apnea syndrome in male patients. Sleep Breath. 2014;18(2):269-74.

29. Dewan NA, Nieto FJ, Somers VK. Intermittent hypoxemia and OSA: implications for comorbidities. Chest. 2015;147(1):266-74.

30. Lanfranco F, Motta G, Minetto MA, Ghigo E, Maccario M. Growth hormone/insulin-like growth factor-I axis in obstructive sleep apnea syndrome: an update. J Endocrinol Investig. 2010;33(3):192-6.

31. Amaral IP, Johnston IA. Circadian expression of clock and putative clock-controlled genes in skeletal muscle of the zebrafish. Am J Physiol Regul Integr Comp Physiol. 2012;302(1):R193-206.

32. Hedner J, Bengtsson-Boström K, Peker Y, Grote L, Råstam L, Lindblad U. Hypertension prevalence in obstructive sleep apnoea and sex: a population-based case-control study. Eur Respir J. 2006;27(3):564-70.

33. Kent BD, Garvey JF, Ryan S, Nolan G, Dodd JD, McNicholas WT. Severity of obstructive sleep apnoea predicts coronary artery plaque burden: a coronary computed tomographic angiography study. Eur Respir J. 2013;42(5):1263-70.

34. Sforza E, Roche F. Chronic intermittent hypoxia and obstructive sleep apnea: an experimental and clinical approach. Hypoxia (Auckl). 2016;4:99-108. 
35. Drager LF, Jun J, Polotsky VY. Obstructive sleep apnea and dyslipidemia: implications for atherosclerosis. Curr Opin Endocrinol Diabetes Obes. 2010;17(2):161-5.

36. Popovici RM, Lu M, Bhatia S, Faessen GH, Giaccia AJ, Giudice LC. Hypoxia regulates insulin-like growth factor-binding protein 1 in human fetal hepatocytes in primary culture: suggestive molecular mechanisms for in utero fetal growth restriction caused by uteroplacental insufficiency. J Clin Endocrinol Metab. 2001;86(6):2653-9.

37. Minchenko DO, Kharkova AP, Halkin OV, Karbovskyi LL, Minchenko OH. Effect of hypoxia on the expression of genes encoding insulin-like growth factors and some related proteins in U87 glioma cells without IRE1 function. Endocr Regul. 2016;50(2):43-54.

38. Al Mutairi S, Mojiminiyi OA, Al Alawi A, Al Rammah T, Abdella N. Study of Leptin and Adiponectin as Disease Markers in Subjects with Obstructive Sleep Apnea. Dis Markers. 2014;2014:706314.

39. Mazerbourg S, Callebaut I, Zapf J, Mohan S, Overgaard M, Monget P. Up date on IGFBP-4: regulation of IGFBP-4 levels and functions, in vitro and in vivo. Growth Hormon IGF Res. 2004;14(2):71-84.

40. Kobayashi T, Kaneda A, Kamata K. Possible involvement of IGF-1 receptor and IGF-binding protein in insulin-induced enhancement of noradrenaline response in diabetic rat aorta. $\mathrm{Br} \mathrm{J}$ Pharmacol. 2003;140(2):285-94.

41. Zhou R, Flaswinkel H, Schneider MR, Lahm H, Hoeflich A, Wanke R, et al. Insulin-like growth factorbinding protein- 4 inhibits growth of the thymus in transgenic mice. $\mathrm{J} \mathrm{Mol} \mathrm{Endocrinol.}$ 2004;32(2):349-64.

42. Kashani K, Al-Khafaji A, Ardiles T, Artigas A, Bagshaw SM, Bell M, et al. Discovery and validation of cell cycle arrest biomarkers in human acute kidney injury. Crit Care (London England). 2013;17(1):R25.

43. Saad A, Wang W, Herrmann SMS, Glockner JF, McKusick MA, Misra S, et al. Atherosclerotic renal artery stenosis is associated with elevated cell cycle arrest markers related to reduced renal blood flow and postcontrast hypoxia. Nephrol Dial Transplant. 2016;31(11):1855-63.

44. Kellum JA, Chawla LS. Cell-cycle arrest and acute kidney injury: the light and the dark sides. Nephrol Dial Transplant. 2016;31(1):16-22.

45. Zarbock A, Schmidt C, Van Aken H, Wempe C, Martens S, Zahn PK, et al. Effect of remote ischemic preconditioning on kidney injury among high-risk patients undergoing cardiac surgery: a randomized clinical trial. Jama. 2015;313(21):2133-41.

\section{Tables}


Table 1

Clinical and anthropometric characteristics of participants at baseline

\begin{tabular}{|c|c|c|c|}
\hline \multirow[t]{2}{*}{ Variable } & \multirow{2}{*}{$\begin{array}{l}\text { Non - OSA } \\
(\mathrm{N}=28) \\
\text { Average } \pm \text { SEM }\end{array}$} & \multicolumn{2}{|l|}{$\begin{array}{l}\text { OSA } \\
(N=39)\end{array}$} \\
\hline & & Average \pm SEM & $P$ - value \\
\hline Age (years) & $43.5 \pm 2.03$ & $40.41 \pm 1.68$ & 0.246 \\
\hline Weight (Kg) & $85.28 \pm 3.51$ & $89.06 \pm 2.30$ & 0.372 \\
\hline Height (cm) & $172.36 \pm 1.8$ & $171.48 \pm 1.13$ & 0.682 \\
\hline $\mathrm{BMI}\left(\mathrm{Kg} / \mathrm{m}^{2}\right)$ & $28.59 \pm 0.99$ & $30.18 \pm 0.63$ & 0.181 \\
\hline Pulse & $73.21 \pm 2.37$ & $77.87 \pm 1.74$ & 0.119 \\
\hline SBP (mmHg) & $125.04 \pm 2.28$ & $125.89 \pm 2.18$ & 0.786 \\
\hline $\mathrm{DBP}(\mathrm{mmHg})$ & $74.75 \pm 1.62$ & $74.13 \pm 1.66$ & 0.79 \\
\hline ESS & $2.33 \pm 0.54$ & $13.45 \pm 1.3$ & $<0.001 * *$ \\
\hline AHI (events/h) & $2.12 \pm 0.26$ & $22.99 \pm 3.39$ & $<0.001$ ** \\
\hline Al (events/h) & $1.18 \pm 0.21$ & $3.01 \pm 0.92$ & 0.064 \\
\hline HI (events/h) & $1.54 \pm 0.28$ & $17.53 \pm 2.74$ & $<0.001$ ** \\
\hline T. Chol (mmol/L) & $4.98 \pm 0.19$ & $5.09 \pm 0.19$ & 0.681 \\
\hline HDL (mmol/L) & $1.25 \pm 0.07$ & $1.08 \pm 0.04$ & $0.037 *$ \\
\hline LDL (mmol/L) & $3.16 \pm 0.18$ & $3.33 \pm 0.18$ & 0.525 \\
\hline TG (mmol/L) & $1.25 \pm 0.11$ & $1.51 \pm 0.15$ & 0.178 \\
\hline GLU (mmol/L) & $5.85 \pm 0.33$ & $5.92 \pm 0.20$ & 0.864 \\
\hline HBA1C (\%) & $5.86 \pm 0.23$ & $5.84 \pm 0.13$ & 0.939 \\
\hline WBC (10^9/L) & $6.58 \pm 0.39$ & $7.07 \pm 0.30$ & 0.335 \\
\hline C-pep (pmol/L) & $2514.62 \pm 291.03$ & $3633.65 \pm 293.32$ & $0.009 * *$ \\
\hline Insulin (U/L) & $7.46 \pm 0.91$ & $10.93 \pm 1.32$ & $0.035^{*}$ \\
\hline IGFBP1 (ng/ml) & $14687.01 \pm 2692.49$ & $10695.42 \pm 1510.3$ & 0.203 \\
\hline IGFBP2 (ng/ml) & $269837.02 \pm 31643.27$ & $213922.55 \pm 12632.2$ & 0.139 \\
\hline IGFBP3 (ng/ml) & $721032.69 \pm 40291.55$ & $756438.94 \pm 30196.72$ & 0.485 \\
\hline $\begin{array}{l}\text { Data are mean } \pm S \\
\text { (ESS) Epworth Sle } \\
{ }^{\star} p<05 ; * * p<01 \mathrm{i}\end{array}$ & $\begin{array}{l}\text { d error mean; (SBP) syst } \\
\text { S Scale; (AHI) Apnea-Hyp } \\
\text { ng high statistical differ }\end{array}$ & $\begin{array}{l}\text { d pressure; (DBP) diasto } \\
\text { ndex; (AI) Apnea Index; }\end{array}$ & $\begin{array}{l}\text { d pressure; } \\
\text { opnea Index }\end{array}$ \\
\hline
\end{tabular}




\begin{tabular}{|c|c|c|c|}
\hline Variable & $\begin{array}{l}\text { Non - OSA } \\
(\mathrm{N}=28)\end{array}$ & $\begin{array}{l}\text { OSA } \\
(N=39)\end{array}$ & \\
\hline IGFBP4 (ng/ml) & $173.35 \pm 20.86$ & $253.65 \pm 20.46$ & 0.008 ** \\
\hline IGFBP7 (ng/ml) & $17622.79 \pm 1810.54$ & $18822.84 \pm 1201.21$ & 0.234 \\
\hline
\end{tabular}


Table 2

Changes in clinical characteristics comparing baseline to 3-months post intervention

\begin{tabular}{|c|c|c|c|}
\hline & $\begin{array}{l}\text { Baseline } \\
(\mathrm{N}=39)\end{array}$ & $\begin{array}{l}\text { Post 3-months } \\
(\mathrm{N}=39)\end{array}$ & \\
\hline Variable & Mean \pm SEM & Mean \pm SEM & $P$ - value \\
\hline Weight (Kg) & $89.06 \pm 2.30$ & $86.46 \pm 2.73$ & 0.178 \\
\hline Height (cm) & $171.48 \pm 1.13$ & $170.40 \pm 1.64$ & 0.490 \\
\hline BMI $\left(\mathrm{Kg} / \mathrm{m}^{2}\right)$ & $30.18 \pm 0.63$ & $29.71 \pm 0.78$ & 0.166 \\
\hline Pulse & $77.87 \pm 1.74$ & $76.81 \pm 2.41$ & 1.000 \\
\hline SBP (mmHg) & $125.89 \pm 2.18$ & $124.62 \pm 2.86$ & 0.518 \\
\hline $\mathrm{DBP}(\mathrm{mmHg})$ & $74.13 \pm 1.66$ & $77.19 \pm 2.19$ & 0.411 \\
\hline ESS & $13.45 \pm 1.3$ & $3.35 \pm 0.58$ & $<0.001 * *$ \\
\hline AHI (events/h) & $22.99 \pm 3.39$ & $8.97 \pm 2.37$ & $<0.001 * *$ \\
\hline Al (events/h) & $3.01 \pm 0.92$ & $1.18 \pm 0.21$ & 0.064 \\
\hline HI (events/h) & $17.53 \pm 2.74$ & $6.63 \pm 1.99$ & 0.201 \\
\hline T. Chol (mmol/L) & $5.09 \pm 0.19$ & $5.01 \pm 0.25$ & 0.664 \\
\hline $\mathrm{HDL}(\mathrm{mmol} / \mathrm{L})$ & $1.08 \pm 0.04$ & $1.11 \pm 0.05$ & 0.839 \\
\hline LDL (mmol/L) & $3.33 \pm 0.18$ & $3.27 \pm 0.26$ & 0.682 \\
\hline TG (mmol/L) & $1.51 \pm 0.15$ & $1.40 \pm 0.09$ & 0.789 \\
\hline $\mathrm{GLU}(\mathrm{mmol} / \mathrm{L})$ & $5.92 \pm 0.20$ & $5.88 \pm 0.23$ & 0.711 \\
\hline HBA1C (\%) & $5.84 \pm 0.13$ & $5.63 \pm 0.11$ & 0.334 \\
\hline WBC (10^9/L) & $7.07 \pm 0.30$ & $6.21 \pm 0.23$ & $0.038 *$ \\
\hline C-pep (pmol/L) & $3633.65 \pm 293.32$ & $3202.32 \pm 229.21$ & 0.221 \\
\hline Insulin (U/L) & $10.93 \pm 1.32$ & $9.49 \pm 0.84$ & 0.507 \\
\hline IGFBP1 (ng/ml) & $10695.42 \pm 1510.3$ & $11407.09 \pm 2218.27$ & 0.678 \\
\hline IGFBP2 (ng/ml) & $213922.55 \pm 12632.2$ & $201469.07 \pm 14709.04$ & 0.231 \\
\hline IGFBP3 (ng/ml) & $756438.94 \pm 30196.72$ & $730163.84 \pm 30757.07$ & 0.435 \\
\hline IGFBP4 (ng/ml) & $253.65 \pm 20.466$ & $225.89 \pm 18.16$ & $0.012^{*}$ \\
\hline \multicolumn{4}{|c|}{$\begin{array}{l}\text { Data are mean } \pm \text { standard error mean; (SBP) systolic blood pressure; (DBP) diastolic blood pressure; } \\
\text { (ESS) Epworth Sleepiness Scale; (AHI) Apnea-Hypopnea Index; (Al) Apnea Index; (HI) Hypopnea Index } \\
{ }^{\star} p<05 ; * \neq<01 \text { indicating high statistical difference. }\end{array}$} \\
\hline
\end{tabular}




\begin{tabular}{|c|c|c|c|}
\hline & $\begin{array}{l}\text { Baseline } \\
(\mathrm{N}=39)\end{array}$ & $\begin{array}{l}\text { Post 3-months } \\
(\mathrm{N}=39)\end{array}$ & \\
\hline IGFBP7 (ng/ml) & $18822.84 \pm 1201.21$ & $19315.96 \pm 1199.77$ & 0.439 \\
\hline
\end{tabular}

\section{Declarations:}

\section{Figures}

A

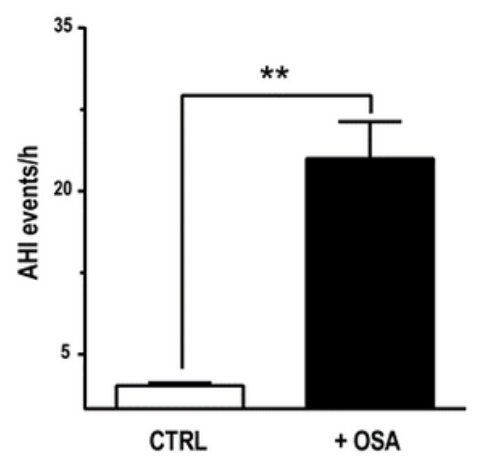

B

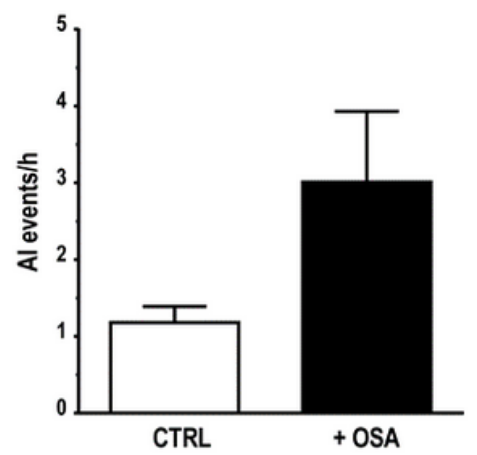

C

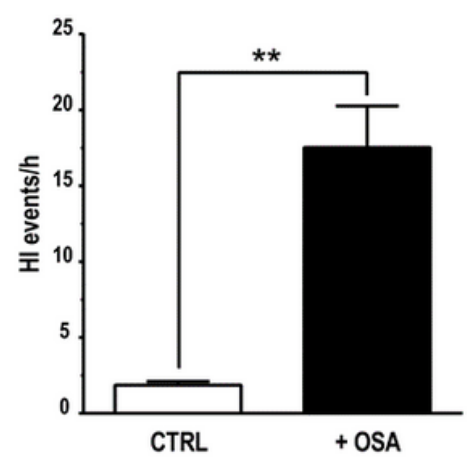

Figure 1

Polysomnography for OSA diagnosis. (A) The apnea hypopnea index (AHI) shows the severity of OSA in people with OSA compared to the control group. (B) The apnea index (AI) reflecting a significant difference in the number of complete paused breathing events in people with OSA in comparison to the control. (C) The hypopnea index $(\mathrm{HI})$ showing a significant increase in the number of shallow breathing events in people with OSA, compared to the control group. 

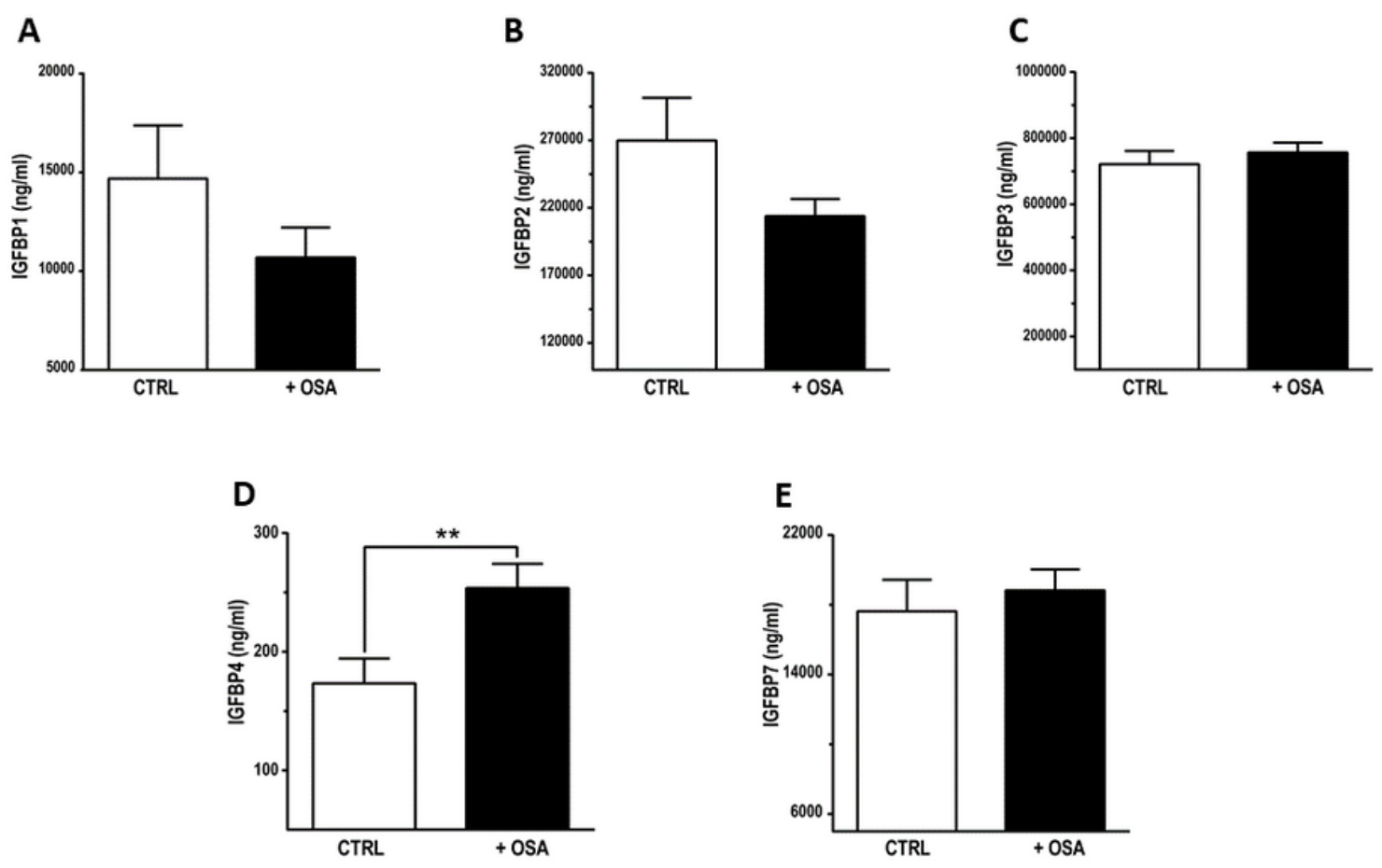

\section{Figure 2}

Comparing baseline levels of circulating IGFBPs in people with and without OSA. (A) IGFBP1 showed no significant difference $(p=0.203)$ between people with OSA $(10695.42 \varangle 1510.3 \mathrm{ng} / \mathrm{ml})$ and control $(14687.01 \otimes 2692.49 \mathrm{ng} / \mathrm{ml})$. (B) IGFBP2 levels were not significantly different $(p=0.139)$ comparing people with OSA $(213922.55 \pm 12632.2 \mathrm{ng} / \mathrm{ml})$ and control $(269837.02 \pm 31643.27 \mathrm{ng} / \mathrm{ml})$. (C) levels of IGFBP3 are comparable between people with OSA $(756438.94 \varangle 30196.72 \mathrm{ng} / \mathrm{ml})$ and control $(721032.69$ $\$ 40291.55 \mathrm{ng} / \mathrm{ml})$. (D) Circulating IGFBP4 was significantly higher $(p=0.008)$ in people with OSA (253.65 $\varangle 20.46 \mathrm{ng} / \mathrm{ml})$ compared to control $(173.35 \varangle 20.86 \mathrm{ng} / \mathrm{ml})$. (E) IGFBP7 levels showed no difference $(p=$ $0.234)$ between OSA $(18822.84 \otimes 1201.21 \mathrm{ng} / \mathrm{ml})$ and control $(17622.79 \otimes 1810.54 \mathrm{ng} / \mathrm{ml})$.

A

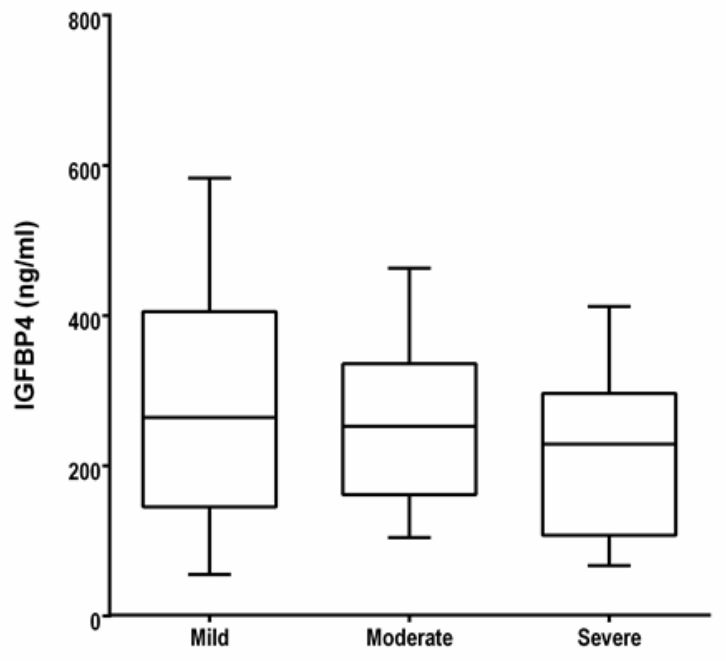

B

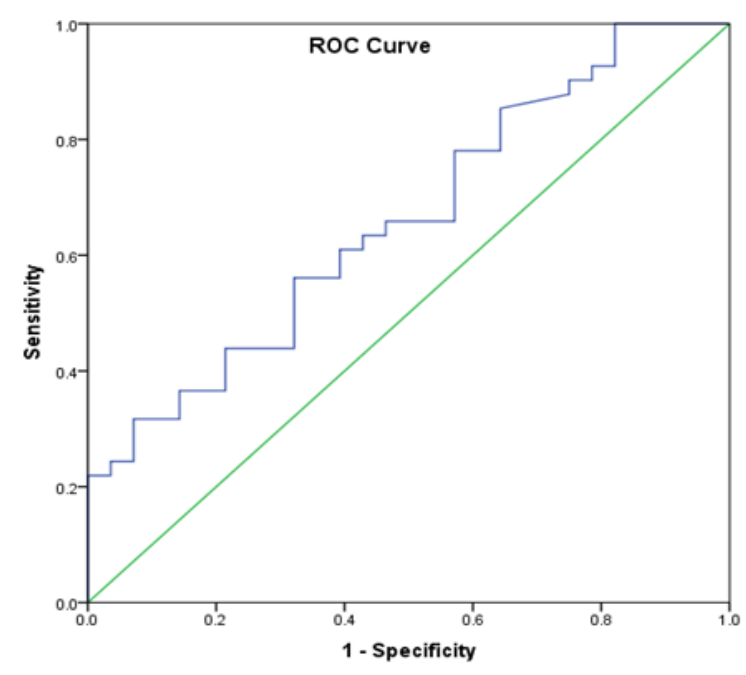




\section{Figure 3}

Levels of circulating IGFBP4 differs with OSA severity and it acts as a predictive marker. (A) Box-andwhisker plot showing levels of circulating IGFBP4 at different OSA severity. IGFBP4 was highest with mild OSA ( $267.93 \pm 36.02 \mathrm{ng} / \mathrm{ml}, \mathrm{n}=18)$ and it declines with increased OSA severity. IGFBP4 levels in people with mild OSA were lower $(254.74 \pm 28.88 \mathrm{ng} / \mathrm{ml}, \mathrm{n}=14)$ in comparison to mild, and it was the lowest in people with severe OSA ( $221.51 \pm 44.7 \mathrm{ng} / \mathrm{ml}, \mathrm{n}=7)$. (B) ROC curve analysis for determining the sensitivity and specificity of circulating IGFBP4 level in as a marker signifying people with OSA.

A

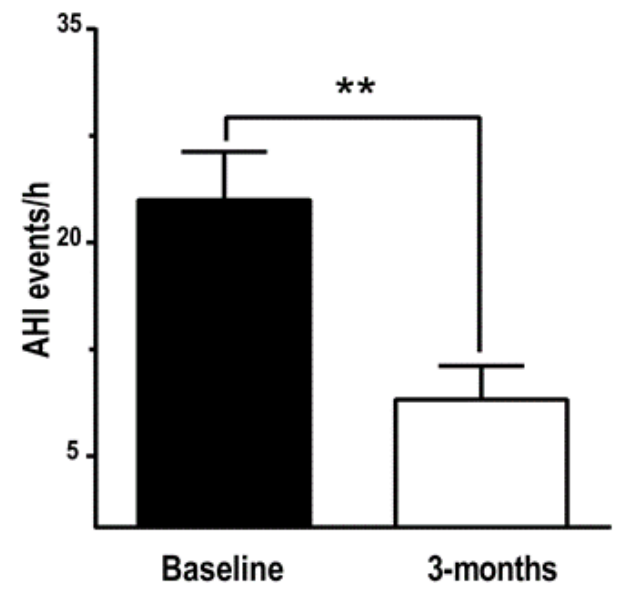

B

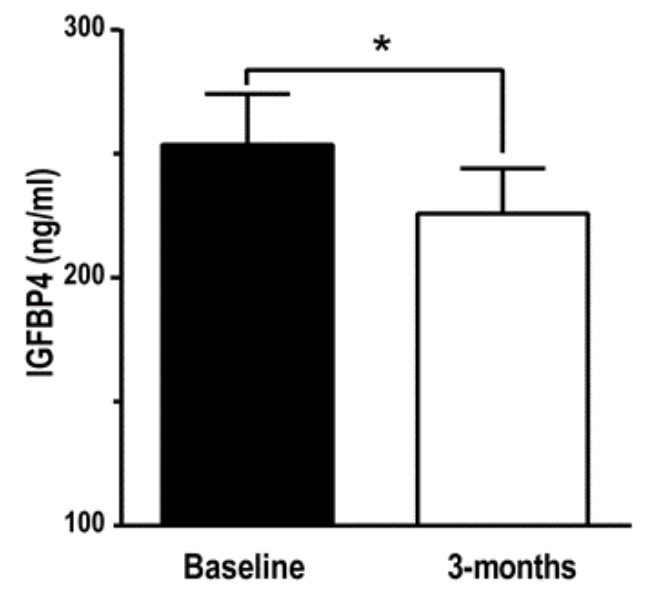

\section{Figure 4}

A significant improvement in AHI and IGFBP4 after 3-months of surgical intervention. (A) A significant decline in $\mathrm{AHI}$ index (10.7 $\otimes 2.3$ events/h, $\mathrm{p}=0.013)$ after 3-months of surgery, reflecting a substantial improvement in OSA. (B) IGFBP4 showed a significant reduction $(225.89 \otimes 18.16 \mathrm{ng} / \mathrm{ml}, \mathrm{p}=0.012)$ after 3months of surgery. 